\title{
UNA MIRADA CRÍTICA Y BENÉVOLA SOBRE ESPAÑA: LE VOYAGE EN ESPAGNE ET EN ALGÉRIE DE JACQUES BOUCHER DE PERTHES (1859)
}

\author{
Aline VAuChelle \\ (Universidad de Rouen / ERIAC)
}

Aceptado: 20-VI-2008.

aline.haquet@wanadoo.fr

RESUMEN: El arqueólogo y filántropo Jacques Boucher de Perthes viajó a España en 1855. El interés del relato que publicó en 1859 reside esencialmente en la mirada de este espiritu práctico sobre la situación económica del país y en las costumbres de los españoles. Por cierto, convencido de la superioridad francesa, critica las disfunciones existentes en los transportes, deplora la desidia imperante, y se queja de la falta de higiene. Pero achaca todas estas lacras al mal gobierno y juzga al pueblo español con indulgencia y benevolencia. Palabras clave: Boucher de Perthes, libros de viajes, relaciones España-Francia, siglo XIX.

ABSTRACT: The archeologist cum philanthropist Jacques Boucher de Perthes travelled in Spain in 1855. The value of the chronicle he published in 1859 lies above all in the way this practical mind considers the country's economic situation and the local costums. Being convinced of the French superiority, he does stigmatize the poor quality of the transport system, deplores a general apathy and complains about the lack of hygiene. However, he puts the blame on bad governance and considers the Spanish people with benign indulgence. Key words: Boucher de Perthes, travel books, Spain-France relationships, nineteenth-century.

Jacques Boucher de Crèvecoeur de Perthes (1788-1868) nació en Rethel, en Ardenas, en una familia noble de gran alcurnia, pero que no sufrió persecuciones durante la Revolución. Su padre, Jules Boucher de Crèvecoeur, afamado naturalista, amigo de Rousseau, Lamarck, Cuvier y Lavoisier, a quienes solía recibir en su casa parisina, perdió una pequeña parte de su considerable fortuna, sin embargo se negó a emigrar durante el Terror. Se mantuvo cautamente al margen de los alborotos políticos, haciéndose llamar llanamente «ciudadano Boucher» y se dedicó más que nunca a su afición 
por la botánica. Concluida la tormenta revolucionaria, fue nombrado director de Aduanas en Abbeville (Picardia) por el Primer Cónsul. ${ }^{1}$

En cuanto a Jacques, se apasionó primero por la literatura y escribió una comedia Le Grand homme chez lui (1828), así como unas tragedias, Frédégonde, Persée de Macédoine y Constantin, que si bien tuvieron a la sazón algún éxito, han caído hoy en día en el más profundo olvido. En rigor, fue como arqueólogo como se granjeó fama y notoriedad. Constituyó una relevante colección de antigüedades romanas y célticas, que más tarde legó al Estado y, persuadido de la existencia del hombre antediluviano, realizó sobre este tema numerosas investigaciones que desembocaron en la publicación de dos obras, varias veces reeditadas, y cuya originalidad e importancia fueron encomiadas por los científicos de la época: De la Création, essai sur l'origine et la progression des êtres (1839-1841, 5 volúmenes en octavo) y Antiquités celtiques et antédiluviennes (1847). ${ }^{2}$ Fue uno de los fundadores de la ciencia prehistórica en Francia.

De pequeño, Jacques vivió un breve período de exaltación religiosa — que él mismo tilda de «fanatismo» en su Correspondance-, juzgando sus pecados con exagerada escrupulosidad e imponiéndose rigurosos ayunos y mortificaciones. Pronto las aguas volvieron a su cauce y Boucher de Perthes practicó a lo largo de su vida un catolicismo sincero, tolerante y caritativo, mostrándose hostil al ultramontanismo y al poder temporal del Sumo Pontífice. ${ }^{3}$

Políticamente hablando, lo podríamos definir como un liberal convencido y a la vez pragmático. Reconoce las admirables dotes militares de Napoleón y tributa homenaje a su genio administrativo, pero rechaza tajantemente su despotismo, culpándole de haber pisoteado la civilización y la libertad, causando así un mal inmenso a Francia y a Europa. ${ }^{4}$ Por eso, pensó que la restauración de los Borbones en 1814 podía ayudar a Francia a superar su crítica situación, siempre que no tolerasen la presencia de los invasores prusianos y rusos, contra los cuales él mismo combatió en las puertas de París, alistándose en la Guardia Nacional..$^{5}$ Patriota fervoroso, Boucher de Perthes afirmaba que no se podía gobernar a un pueblo degollándolo o dejándolo degollar. ${ }^{6} \mathrm{~A}$ todas luces, aceptó el regreso de la antigua dinastía sin entusiasmo, como un mal menor, y lamentaba que Luis XVIII se dejase manejar por la Santa Alianza — a la que él llama la «Maldita» Alianza-, pues ésta incitó al Rey a suprimir los aspectos positivos del régimen napo-

\footnotetext{
'Jacques Boucher de Perthes: Correspondance de -, témoins de dix règnes, éditée par $\mathrm{H}$. et J. Perchellet, Le Raincy, Les Éditions Claires, 1947, pp. 16, 40 y 58.

${ }^{2}$ Pierre Larousse: Grand dictionnaire universel du XIXè siècle, Genève-Paris, Slatkine, 1982. Véase también Catalogue des livres imprimés de la Bibliothèque Nationale de France.

${ }^{3}$ Ibid., pp. 32, 136-138.

${ }^{4}$ Ibid., pp. 155-156.

s Ibid., pp. 125 y 155 .

${ }^{6}$ "On ne peut gouverner le peuple qu'on égorge ni qu'on laisse égorger», Ibid., p. 143.
} 
leónico y a dejar rienda suelta a un clero ambicioso y a unos realistas estúpidos, a quienes Boucher de Perthes consideraba más perjudiciales para la realeza que el jacobinismo. ${ }^{7}$ De ahí que deplorara la muerte del duque de Berry, dado que éste no podía sufrir a los ultras. ${ }^{8}$

En 1825, Jacques sucedió a su padre en el cargo de Director de Aduanas de Abbeville y, en 1830, sintiéndose sometido a discreción por respeto a su estatuto de funcionario, se abstuvo de tomar parte activa en la Revolución de las Tres Gloriosas. Empero, se alegró de Ia caída de Carlos $\mathrm{X}$ y del gobierno reaccionario de Polignac. ${ }^{9}$ Como hombre del «justo medio» que era, Boucher de Perthes se adhirió sinceramente al nuevo rey, Luis Felipe. Fue convidado varias veces por la Familia Real a comer en su residencia del castillo de Eu y elogia la sencillez del modo de vivir de sus huéspedes. A los ojos de nuestro autor, el «rey ciudadano» es, con Luis XVI, el mejor de los padres de familia y el soberano francés de mayor moralidad. Lo juzga como un hombre muy culto y dotado de una gran voluntad, pero pragmático. ${ }^{10}$ En buena lógica, pues, cuando la revolución de febrero de 1848, Boucher de Perthes empezó por recelar de la República, temiendo que provocara un caos, un terremoto, cuyas víctimas serían, como siempre, las masas pobres. Sin embargo, no tardó en cambiar de parecer y, en abril, pensaba que la República era la única tabla de salvación para acabar con el pasado, siempre que fuera una república sabia, que se cuidara de evitar todo cuanto recordara $1793 .{ }^{11}$ Entonces el Director de Aduanas decidió olvidarse de sus escrúpulos de funcionario y salió a la palestra política, presentando su candidatura para diputado, pero no resultó elegido, por cuanto los ultramontanos se movilizaron en su contra. En los comicios presidenciales de diciembre, Boucher de Perthes votó a favor de su amigo Lamartine, «el hombre más honrado» que conocía. Y, si bien consideraba a Luis Napoleón Bonaparte como un hombre capaz, sospechaba que éste restauraría el imperio lo que, en su opinión, significaba guerra o gobierno militar, o sea el peor de los gobiernos. ${ }^{12}$ Por consiguiente, desaprobó el golpe de Estado de diciembre de 1851, lo que le mereció ser cesado por las autoridades del Segundo Imperio. ${ }^{13}$

${ }^{7}$ Ibid., p. 156.

${ }^{8}$ Ibid., p. 164.

${ }^{9}$ Ibid., p. 178.

${ }_{10}$ «D'une instruction profonde, parlant l'anglais et l'italien comme sa propre langue, ce fut, avec Louis XVI, le meilleur père de famille et le roi le plus moral qu'ait eu la France. Il a une volonté tenace, mais qui sait se ployer aux circonstances et descendre une marche, et même deux, pour en monter trois", Ibid., p. 192.

${ }_{11}$ "Donc "Vive la République”; je ne vois pas d'autre moyen de sortir du passé. Si la République est sage, si elle a soin d'éviter ce qui rappelle 1793, si elle sait donner une bonne constituante, elle pourra vivre», Ibid., pp. 209-210.

${ }_{12}$ «(Napoléon) est un homme fort capable, mais voter pour lui, c'est voter pour l'empirc... Quant à moi, je le dis, "assez d'empirc", car l'empire c'est la guerre, ou le gouvernement militaire, le pire des gouvernements", Ibid., pp. 214-215.

${ }^{13}$ Ibid., p. 222. 
En concreto, Jacques Boucher de Perthes aparece como un cristiano liberal y social. Todas sus ideas y actitudes traducen un profundo afán por la defensa de las libertades y por el bien de la nación y, por muy holgada que fuera su situación económica, reprobó el capitalismo desenfrenado imperante en la Francia de la época. En contraste, siempre se mostró muy preocupado por la condición de los más humildes y se desveló por luchar contra las injusticias sociales, señaladamente a través de la creación de la Sociedad de Emulación de Abbeville (Somme), cuyo objetivo principal era proporcionar trabajo y auxilio a los necesitados. De este compromiso filantrópico, nos dan una cabal prueba los distintos discursos que pronunció para exhortar a sus conciudadanos a erradicar el pauperismo, entre los cuales podemos destacar: De la misère (1838), Du Patronage, ou de l'influence par la charité (1846) así como De la femme dans l'état social, de son travail et de sa rémunération (1859). ${ }^{14}$

Como nunca se había casado y no tenía hijos, dejó su fortuna a dicha sociedad filantrópica, encargándole que repartiera una parte de ella entre unas muchachas pobres que se dedicaban a criar a sus hermanos. ${ }^{15}$

El Voyage en Espagne et en Algérie salió a luz en $1859,{ }^{16}$ en la prestigiosa librería parisina Treutell y Wurtz, que desde su creación en 1772 en Estrasburgo (Alsacia) se había especializado en la edición y comercialización de libros de geografía y de relatos de viaje, antes de dedicarse también a la de obras históricas y políticas. ${ }^{17} \mathrm{La}$ obra de nuestro arqueólogo consta de nada menos de 612 páginas en octavo, esmeradamente impresas, y su preciosa encuadernación es de vitela. Todo lo cual hace de ella un auténtico artículo de lujo, cuyo precio lamentamos desconocer, pero la Bibliographie de la France omitió mencionarlo ${ }^{18}$ y en la Biblioteca Nacional de Francia no se conservan los catálogos de la librería Treutell y Wurtz posteriores a 1855.

En puridad, el viaje lo había realizado Boucher de Perthes cuatro años antes de publicar el texto. Su estancia en España fue muy breve: cruzó el Pirineo el 31 de agosto de 1855 y el 12 de septiembre embarcó en Santa Pola (Alicante) con rumbo a Argelia, donde llegó el 19 con la intención de visitar un emplazamiento arqueológico en el Atlas, cerca de Argel. El 16 de octubre, estaba de regreso en Abbeville. Su recorrido por la

${ }_{14}^{14}$ Catalogue des livres imprimés de la Bibliothèque Nationale de France.

${ }^{15}$ Jacques Boucher de Perthes: un découvreur à découvrir. Actes du colloque d'Abbeville, I988, organisé par la Société d'Émulation et par la Direction des antiquités préhistoriques de Picardie, Abbeville, Société d'Émulation, 1997, 160 pp.

${ }^{16}$ Jacques Boucher de Perthes: Voyage en Espagne et en Algérie, 1855, Paris, Treuttel et Wurtz, 1859, 612 pp.

${ }^{17}$ Frédéric Barbier: «Une librairie "internationale": Treutell et Wurtz à Strasbourg, Paris et Londres» en Revue d'Alsace, $\mathrm{n}^{\circ} 111$, Strasbourg, Fédération des Sociétés d'Histoire et d'Archéologie d'Alsace, 1985, pp. 111-123.

${ }^{18}$ Bibliographie de la France ou Journal général de l'imprimerie et de la libratrie, Paris, Pillet aîné imprimcur, 1859. 
península se limita, pues, a San Sebastián, Burgos, Madrid, Valencia y Alicante. Por ende, a diferencia de los románticos, nuestro viajero no salió en pos del exotismo oriental que, para muchos de ellos, alcanzaba su cenit en Andalucía. En cambio, en su relato descuella una preocupación mucho más funesta: la epidemia de cólera que, a la sazón, hacía estragos en el país. Otro rasgo dominante en su narración es que, a semejanza de sus compatriotas que viajaron a España en aquel entonces, se muestra muy imbuido de la superioridad francesa. Así, no bien ingresa en España, declara que los campos alrededor de Irún tienen un aspecto pintoresco y que gracias al influjo del país vecino, no se ha renunciado a cultivarlos. ${ }^{19}$ Desde la misma óptica, estima que San Sebastián es una ciudad linda y elegante: tras su destrucción por los ingleses en 1813, ha sido reconstruida acorde al gusto galo, por lo que ya no tiene nada que ver con una ciudad española, sino que es limpia y bien ventilada. De paso, menciona que no lejos del balneario nació Ignacio de Loyola, el fundador de la Compañía de Jesús, a la que no se molesta por dar un arañazo, calificándola de «temible milicia».20

De forma general, no se explaya en la descripción de los paisajes, en contraste con lo que hicieron, entre otros, el marqués de Custine, Théophile Gautier, Alexandre Dumas o George Sand, quien, por mucho que tronaba contra la codicia y la falta de compasión de los mallorquines, no por eso dejaba de admirar la suntuosidad de la naturaleza en la isla. ${ }^{21}$ Aunque escribe con soltura y elegancia, Boucher de Perthes es un espíritu práctico antes que un literato y repara esencialmente en la feracidad o aridez de una comarca y en si se la cultiva con esmero o con desidia. ${ }^{22}$ También resultan bastante sucintas sus relaciones sobre la ciudades: a propósito de Burgos, se contenta con afirmar que no es una ciudad hermosa, aunque le queden unos monumentos dignos de interés, como el ayuntamiento y el palacio de Velasco y sobre todo, la catedral, que a sus ojos, merece toda su fama. Le maravillan las esculturas del pórtico así como las dos torres con sus agujas, y estima que el interior es tan espléndido como la fachada, pero tampoco se detiene en reseñarlo con detalle. ${ }^{23}$

En lo tocante a Madrid, considera que con sus 300000 habitantes no pasa de ser una ciudad de provincias y le deja atónito el bullicio de la muchedumbre que corre por todas

${ }^{19}$ «Les campagnes environnantes ont un aspect assez pittoresque, et le voisinage de la France fait qu'on n'y pas encore renoncé entièrement à la culture», Ibid., p. 67.

${ }^{20}$ Ibid., p. 68.

${ }^{21}$ Astolphe Custine: L'Espagne sous Ferdinand VII, Paris, Ladvocat, 1838, 4 vol in- $8^{\circ}$, (réédition Paris, F. Bourin, 1991, 671 pp.); Théophile Gautier: Voyage en Espagne, réédition Paris, Julliard, 1964, 424 pp.); Alexandre Dumas: Impressions de voyage de Paris à Cadix, Paris, Garnier frères, $1847-1848,5$ vol in- $8^{\circ}$; George Sand: Un hiver à Majorque, Palma de Mallorca, Editorial Clumba, 1968, 192 pp.

${ }^{22}$ A proximidad de Miranda del Ebro: «Le pays environnant est inculte, dépouillé d'arbres et de verdure. On se croirait dans un désert»... A la salida de Burgos: «Les champs qui bordent le chemin ne sont labourés que par place; partout où il $\mathrm{y}$ a une pierre ou un trou, $\mathrm{o}$, ne laboure pas: c'est la méthode du pays. Ailleurs, on aurait ôté la pierre el bouché le trou», J. Boucher de Perthes: Voyage..., pp. 87 y 95.

${ }^{23}$ Ibid., p. 93. 
partes y se da empellones, aunque sin tener otra actividad que gritar o cantar..$^{24}$ Los alrededores no le agradan nada: la corte está construida en una llanura estéril y el Manzanares no es sino un pobre torrente que apenas tiene agua cuando llueve. En cambio, sí reconoce que unas calles son bonitas, las de Toledo, Fuencarral, la calle Mayor, pero deplora la mugre. La que más le gusta es la calle de Alcalá con sus casas señoriales y su hermosa perspectiva a la conocida puerta erigida por Carlos III. ${ }^{25}$ En cuanto al Palacio Real, se ciñe a aseverar que es monumental, empero le cae en gracia la fachada de la ópera. ${ }^{26}$ Como buen arqueólogo, visita el Museo de Historia Natural, cuyas colecciones le parecen muy escasas, pero recalca la presencia de una pieza única que le cautiva: el esqueleto de un megaterio, especie de elefante antediluviano procedente del Paraguay, que está en perfecto estado de conservación. Agasajado por los subdirectores del Museo que le enseñan unos manuscritos raros e interesantes, tiene el gusto de comprobar que sus obras históricas ocupan un lugar destacado en la biblioteca. ${ }^{27}$ Se hace lenguas del Jardín Botánico, que no sólo encuentra digno de interés, sino hasta de estudio. ${ }^{28}$ Visita con curiosidad la Real Armería, donde se pueden contemplar las espadas de numerosos egregios personajes, desde la del Cid hasta la de Cervantes, pasando por las de la reina Isabel de Castilla y de Pedro el Cruel. Tampoco faltan las armaduras de Boabdil, de Felipe II, de don Juan de Austria, de Cristóbal Colón, de Hernán Cortés, ni las de distintos prelados, entre las que sobresale la del cardenal Cisneros. Todas son tan finamente labradas que se asemejan más bien a adornos que a pertrechos de guerra. Y nuestro filántropo no puede evitar pensar en el dineral que se despilfarró en ellas y en los años de trabajo que costó cada una. ${ }^{29}$ En las caballerizas reales algunos carruajes le parecen verdaderamente primorosos, en especial la carroza de la Corona, fabulosamente adornada y enteramente forrada de seda bordada a mano. Entre la ingente colección de jaeces, un sinnúmero de ellos están chapados de oro o platino, otros son de plata maciza, y las libreas de los domésticos, tanto como los caparazones de los caballos, están recargados de trencillas y de bordados de oro fino. De nuevo, Boucher de Perthes juzga excesivo tamaño derroche, pero observa que la mayoría de estos perendengues de lujo se transmitieron de un monarca a otro y, por lo menos, su excelente calidad permitió no dilapidar más dinero todavía para reponerlos. ${ }^{30}$

Resulta algo sorprendente que nuestro viajero se dedique primero a ver armas y carruajes, en vez de acudir al Museo del Prado, como lo hacían - y lo siguen hacien-

\footnotetext{
${ }^{24}$ Ibid., p. 112.

${ }^{25}$ Ibid., p. 134.

${ }^{26}$ Ibid., pp. 113 y 115 .

${ }^{27}$ Ibid., p. 114.

${ }^{28}$ Ibid., p. 134.

${ }^{29}$ Ibid., pp. 115-117.

${ }^{30}$ Ibid., pp. 118-120.
} 
do - todos los extranjeros nada más llegar a la corte. Pero cuando se determina a visitarlo, confiesa que estaba muy mal informado. Creía que, a raíz de los saqueos perpetrados por la soldadesca napoleónica en tiempos de la Guerra de la Independencia, no quedaba casi nada en las colecciones pictóricas españolas. ${ }^{31}$ En realidad, le deslumbran el número y la calidad de los lienzos, le seduce particularmente el talento de Velázquez, de Ribera y de Murillo y reconoce que la pinacoteca madrileña es una de las más ricas que existen. ${ }^{32}$ Por supuesto, al salir del museo, da una vuelta por el famoso paseo colindante cuya belleza estima a la altura de su reputación, pero, en contra de lo que había oído decir, observa la escasez de personas y de carruajes elegantes. Lo achaca al cólera que ha inducido a la mayoría de la gente adinerada a huir de la capital, así como a los disturbios políticos entonces existentes en España que incitan a los ricos a ocultar su fortuna ${ }^{33}$ - se refiere a la conflictividad social generada por la impaciencia del pueblo ante el incumplimiento de las promesas que habían hecho los progresistas cuando tomaron el poder el año anterior-.

En Aranjuez, alaba la pulcritud de la ciudad, que compara con un «pequeño Versalles burgués». El palacio le parece ser más bien una casa solariega que una residencia real, empero le encantan los jardines a la inglesa así como sus hermosas fuentes, y expone una versión muy personal e irónica del consabido motín de 1808. Según lo que cuenta, Carlos IV, forzado por la insurrección a optar entre el trono y el favorito de la Reina, abdicó para salvar a Godoy, dando así una inaudita prueba de amor conyugal y de abnegación. ${ }^{34}$

Mientras se va acercando a Valencia, Boucher de Perthes nota con mucha satisfacción que el campo está muy cuidadosamente cultivado y que, gracias al riego, la tierra abunda en espléndidos frutales, señaladamente unos naranjos que, según afirma, son tan grandes como los mayores manzanos normandos. También aprecia la profusión de soberbios nogales, moreras, algarrobos, olivos y viñedos. Y ¡cómo no!, aprovecha la ocasión para censurar, una vez más, la dejadez predominante en otras regiones, asegurando que los ojos, heridos por la esterilidad, o más bien por la incuria de los hombres, por fin descansan con agrado en esta comarca, donde todo revela el trabajo y la prosperidad. $^{35}$

${ }^{31}$ «J'avais si souvent entendu dire que l'Espagne avait ćté dépouillée de tous ses chefs-d'œuvre et qu'il n'y avait pas un général français, pas même un colonel, qui n'eât emporté un riche collection, que j'étais convaincu qu'il n'en restait plus un seul (Lableau) qui valut la peine d'être regardé», Ibid., p. 120.

${ }^{32}$ Ibid.

${ }^{33}$ "La richesse se cache, quand la pauvreté règne», Ibid., p. 122.

${ }^{34}$ "On sait que c'est à Aranjuez que Charles IV fut contraint, par une insurrection, d'opter entre sa couronne et son favori, ou plutôt le favori de la reine, Manuel Godoy, et ce fut pour Godoy qu'il opta. Voilà un bel et rare exemple d'amour conjugal: on a vu des maris pardonner à l'amant de leur femme, mais céder leur couronne pour sauver cet amant, c'est le sublime de l'abnégation", Ibid., p. 149.

${ }^{35}$ Ibid., pp. 167 y 175. 
En la ciudad del Turia, llama su atención el gran encanto de las mujeres. Le agrada «infinitamente» la catedral y, a pesar de la lluvia, Valencia le parece bella. No obstante, estima que calificarla de urbe industrial y mercantil quizá sea válido en España, pero resultaría excesivo en Francia y aún más en Inglaterra. El problema es que en materia de arte, ciencia, comercio e industria, los españoles se contentan con producir una cuarta parte de lo que podrían hacer, por cuanto, ya sean ricos o pobres, piensan ante todo en darse una buena vida. ${ }^{36}$

Como castigo de tan severo juicio, a nuestro viajero le espera un terrible infortunio después de embarcar desde Valencia a Alicante. Puesto que hay casos de cólera en Valencia, quienes vienen de allí no pueden penetrar en Alicante, sin permanecer previamente en cuarentena en una casa sanitaria, a corta distancia de la ciudad. El relato de Boucher de Perthes es verdaderamente escalofriante por la total falta de higiene que impera en lo que tendría que ser, según sus propias palabras, «un templo de la salud». ${ }^{37}$ Las veintitrés personas que viajaban a bordo del barco están amontonadas en dos dormitorios exiguos, desprovistos de muebles, aparte de algún jergón asqueroso y sin manta, en los que nada está previsto ni para guarecer el pudor de las damas, y cuyo suelo está cubierto de todo tipo de inmundicias, desde papeles y trapos grasientos hasta huesos roídos y putrefactos, pasando por cáscaras de fruta y residuos de queso que, por cierto, hacen la felicidad de una legión de alimañas e insectos, a cual más repelente. ${ }^{38}$ Tampoco son atractivos los encargados de custodiar a los posibles enfermos. En puridad, no tienen el menor conocimiento médico, son unos brutos y ladrones que hurtan sin escrúpulo el dinero y las prendas de vestir en los equipajes y que desuellan a sus «huéspedes» a la hora de facilitarles algo de comer, dado que nada está organizado con este fin y cada uno tiene que arreglárselas como pueda, incluso para conseguir un poco de agua. Tras pasar una noche en vela por culpa de las pulgas y de los mosquitos, Boucher de Perthes se queda pasmado al enterarse de que unos distinguidos alicantinos y alicantinas vienen a hacer visitas desde la playa a sus conocidos "presos» en el lazareto - «carcere duro» como lo denomina nuestro autor-, hasta compartiendo con ellos alimentos que les regalan por las ventanas. ${ }^{39}$ Le enfurece tan estúpida cuarentena que, en realidad, no impide en absoluto el contacto entre los reclusos y la gente de fuera y recrimina el proceder de la administración sedicente «sanitaria» que tolera los abusos a los que están sometidos los infelices viajeros. Por ende, opina que si el gobierno

${ }^{36}$ «Valence est qualifiée de cité commerçante et industrielle. Cela est vrai en Espagne, mais ne le serait qu'à moitié en France et pas du tout en Angleterre. Tout est relatif: la vérité est que l'Espagne, en choses d'art, de science, de commerce et d'industrie, ne fail pas le quart de ce qu'elle pourrait faire. Le goût dominant, goût que partagent toutes les classes, riches ou pauvres, est de prendre du bon temps», Ibid., p. 190.

${ }^{37}$ Ibid., p. 228.

${ }^{38}$ Ibid., pp. 232-233.

${ }^{39}$ Ibid., pp. 234-261. 
español quiere ponerse a la altura de los países civilizados, tiene que remediar esos desmanes y no consentir que unas personas honorables sufran malos tratos que en otros países ni siquiera se infligen a los malhechores. ${ }^{40}$ Afortunadamente sus deseos fueron satisfechos y los guardas recibieron la orden de soltar a sus «víctimas». De este modo, la llamada «cuarentena» terminó al cabo de un día.

Si Boucher de Perthes repara mucho en los aspectos utilitarios de la vida en España, no por eso desdeña por completo los elementos más pintorescos. Desde luego, a diferencia de Théophile Gautier, quien era muy aficionado a las corridas de toros y las describe con todo detalle, él no reseña ninguna, por el motivo sencillo de que, debido al cólera, han sido momentáneamente suprimidas. Además, no le hacen ninguna gracia y las considera como «carnicerías». ${ }^{41}$ En cambio, en Santa Pola, mientras está esperando un barco que lo lleve a Argelia, asiste a un encierro, del que da cuenta admirando la soltura, el vigor y el brío del toro. ${ }^{42}$ También menciona un tema que se había convertido en tópico, cuando no en leyenda, en todas las relaciones de viaje a España: la consabida omnipresencia de salteadores de camino. Ahora bien, si alude repetidamente al temor que infunden los bandoleros, a la postre relativiza la realidad de su existencia y de su peligrosidad. Sólo una vez, mientras iba camino a Madrid, la diligencia en la que viajaba fue detenida por cuatro sujetos de mala ralea, pero se limitaron a pedir al mayoral la lista de los pasajeros y del cargamento y, no encontrando nada que les satisficiera, se fueron tranquilamente. ${ }^{43}$

En rigor, amén de preocuparse por el aspecto boyante o decadente de la economía en las comarcas por las que atraviesa, lo que más interesa a nuestro autor, como humanista que es, son la vida cotidiana, las costumbres y el carácter del pueblo español.

A este respecto, su veredicto difiere poco de lo que ya escribieron antes otros viajeros extranjeros. Se queja del pésimo estado de los caminos, de la lentitud de los transportes, de lo incómodo y de la suciedad de los coches, así como del tren que toma para ir de Madrid a Albacete. Pero, lo que sin disputa lo afecta más son los usos culinarios. Nota repetidas veces que los españoles suelen ser muy sobrios, que comen poco y que no se entregan a la bebida, cosa que alaba francamente. Sin embargo, a sus 67 años, no cabe duda de que Boucher de Perthes es un hombre todavía atlético, que se da largas caminatas para visitar las ciudades y que tiene una irrefrenable inclinación — bastante rara en aquella época — a tomar baños y nadar lo más posible, apenas

${ }^{40}$ «Et l'administration qui dirige un tel établissement a le front de s'appeler «sanitaire»! Et ce conservatoire de la peste est réputé un lieu de salubrilé et la garantie de la santé publique! Honte à ce qui tolèrent de pareils abus... Si ce gouvernement se respecte, s'il veut se mettre à la hauteur des pays civilisés, qu'il remédie au mal... et qu'on ne fasse pas à des voyageurs honorables ce qu'ailleurs on ne fait pas aux malfaiteurs", Ibid., p. 256.

${ }^{41}$ Ibid., p. 126.

${ }^{42} 1$ bid., pp. 320-322.

${ }^{43}$ Ibid., p, 101. 
vislumbra el mar o incluso un riachuelo que no esté totalmente en seco. Por consiguiente, la comida española nunca sacia su apetito, siempre se queda con las ganas. Fulmina contra los supuestos hoteles de primera categoría cuya cocina, en su opinión, ni siquiera equivale a la de las peores tabernas galas. Echa pestes contra los mesoneros, tan desaliñados y patibularios como la mayoría de sus huéspedes, y que siempre le cobran más caro que a éstos so pretexto de que es extranjero, aunque se molestan muy poco en atenderle. ${ }^{44} \mathrm{Le}$ desespera la falta de variedad de los manjares; para él, son todos «inexplicables guisos» y «pepitorias moriscas», a base de gallina vieja y dura, con salsas excesivamente salpimentadas, al paso que el vino, espeso y casi negro, abrasa el paladar y él sólo logra beber algunos sorbos aguándolo. ${ }^{45}$

En Santa Pola, se aloja en casa de Parés, el encargado de correos y cuñado del vicecónsul, quien no puede hospedarle personalmente, dado que su mujer ha contraído el cólera. Parés es un joven de 25 años, inteligente e instruido, cuya familia es acomodada y muy acogedora. A la hora de cenar, le sirven la habitual olla podrida y le asombra que no haya ni plato ni más cubiertos que unas cucharas de madera de que los comensales se valen para comer todos directamente de la fuente. Por fortuna, el ama de casa entiende su desconcierto y le saca de apuro, dándole a él un pequeño tenedor de hierro, un platillo y un vaso, pues tampoco sabe usar el porrón, el único utensilio existente para apagar la sed. De postre, sacan del cajón de la mesa un trozo de bacalao seco, que a él no le apetece probar por el olor que despide y después de ingerir ya todas las fuertes especias del guisado. ${ }^{46}$

Si no le complace la dieta de los españoles, en cambio, sí le seduce su modo de vestir tradicional. Admira el garbo de un simple mayoral, quien lleva con mucha distinción un traje ceñido de terciopelo azul pulcrísimo, adornado con múltiples botones en forma de media luna, y unas medias cuyo color va perfectamente a juego con su indumentaria. ${ }^{47}$ Del mismo modo, encarece la elegancia natural de las españolas, cuyo traje ligero, adecuado para el clima y para sus graciosos ademanes, pone de realce sus gentiles formas, que la mantilla no esconde. En contraste, lamenta que en las ciudades algunas damas abandonen esta exquisita prenda para seguir la moda parisina, luciendo sombreros que ocultan sus magníficas cabelleras y les dan el aspecto de muñecas. Así parecen estar disfrazadas y, por añadidura, arruinan la originalidad de la cultura española. ${ }^{48}$

${ }^{44}$ Ibid., pp. 69-70, 98.

${ }^{45}$ Ibid., pp. 161, 177.

${ }^{46}$ Ibid., pp. 311-312, 346.

${ }^{47}$ Ibid., p. 165.

48 «ll faut véritablement qu'elles soient folles, elles à qui Dieu a donné une si admirable chevclure, pour l'emprisonner dans cette boite enrubannée, dont la fraîcheur, sous ce soleil brûlant, ne dure pas deux jours; ainsi travesties, elles ne sont plus espagnoles et elles ne sont pas françaises: ce sont des poupées de mode... Partout, on aime à singer la France: c'est très flatteur pour nous, mais ce n'est pas un profit pour l'étranger qui perd ainsi son originalité», Ibid., pp. 153, 285-286. 
En lo tocante al carácter de los moradores, nuestro arqueólogo no se arredra por machacar unos prejuicios muy manidos, empezando por su tan cacareada altivez: hasta los mendigos son tan orgullosos que aparentan hacer el favor de aceptar una limosna, juzgando que son ellos quienes abren las puertas del Paraíso al donante. ${ }^{49}$ Más aún, aludiendo a los problemas políticos, Boucher de Perthes dictamina que a los españoles les gusta degollarse mutuamente, pues tienen un instinto de lobo. ${ }^{50}$ Para remate, al observar cómo unos colegiales bien vestidos apalean con saña unas mulas que se niegan a ponerse en marcha, afirma que, cualquiera que sea su categoría social, su edad o su sexo, los españoles nacen con un alma de verdugo y les encanta ver sufrir y hacer sufrir. ${ }^{51}$ De ahí su afición por las corridas de toros $y$, antaño, por los autos de fe, en que estos extraños cristianos contemplaban las contorsiones de los ajusticiados. ${ }^{52}$ Por lo menos, nuestro autor admite que los habitantes suelen ser menos ariscos y más hospitalarios en los puertos que en las ciudades del interior, por cuanto el contacto con los extranjeros los hace más humanos. Y, luego, acaba reconociendo que, a pesar de ser primero brutales, los españoles no tardan en encariñarse con uno. ${ }^{53}$ Encomia muy especialmente a las mujeres, alegres, valerosas, afectuosas y de buena complexión, en quienes ve dechados de esposas virtuosas y de madres excelentes, hasta el punto de aconsejar que se favorezcan los matrimonios con los franceses, lo que resultaría muy benéfico para evitar la degeneración de las familias. ${ }^{54} \mathrm{Y}$, haciendo alarde de su ignorancia acerca de España, Boucher de Perthes añade que, ahora cuando los varones han pasado de ser gazmoños a filósofos, e incluso más de lo conveniente, son ellas, las mujeres, las que se encargan de rezar por toda la familia. Con todo, en una iglesia alicantina, advierte que no todas cumplen debidamente tan sagrada misión y le asombra comprobar que las feligresas, ricamente vestidas, hacen tertulia, charlando y abanicándose con estrépito, sin prestar la menor atención al sermón del predicador. ${ }^{55}$

Así y todo, por muy severos que sean los juicios de nuestro viajero a propósito de los españoles en general, cabe matizarlos, pues suele achacar la responsabilidad de los defectos que censura al mal gobierno, no al pueblo. No le cabe duda de que España podría ser un país próspero y sus moradores - que fueron industriosos-, volverían a serlo si tuvieran buenas leyes y buenos dirigentes, pero, en su opinión, ningún otro gobierno hace menos en beneficio de los gobernados. ${ }^{56}$ De ahí que Boucher de Perthes,

${ }^{49}$ Ibid., p. 90.

${ }^{\text {so }}$ Ibid., p. 137.

st Ibid., p. 89.

52 Ibid., p. 134.

${ }^{53}$ Ibid., pp. 297 y 349.

54 Ibid., pp. 199-200.

55 Ibid., pp. 190 y 283.

${ }^{56}$ «A quel point de prospérité ne serait pas ce pays, s'il avait un bon gouvernement et de bonnes lois? L'Espagnol a été industrieux, pourquoi ne le redeviendrait-il pas?... Je ne connais pas de gouvernement qui 
pese a su hostilidad hacia el despotismo napoleónico, lamente que en España no se haya impuesto el Código Civil y que, tras la caída del Emperador, se haya restablecido un poder retrógrado, a semejanza de lo que ocurrió en Alemania o Italia, cosa que les cuesta muy cara a estas naciones. ${ }^{57}$

Por consiguiente, cuando llega a Argelia, nuestro autor se siente feliz de abandonar una tierra donde todo es decadencia, y de ver cómo en la colonia está renaciendo la civilización, por obra y gracia de la administración francesa. De hecho, todo le parece mucho más floreciente y mejor en Argelia que en España, desde la economía hasta la comida, abundante, sabrosa y barata, pasando por la limpieza. ${ }^{58}$ Como intelectual de su época que es, participa plenamente de la ideología colonialista que pretendía llevar la cultura y unos valores universales y progresistas a unas regiones sumidas en la barbarie. A sus ojos, entre España y el África francesa media toda la diferencia entre un país que está muriendo y otro que está naciendo. Argelia sale del salvajismo, mientras España está regresando a él: los galos devuelven a los moros lo que ellos habían dado al mundo: la civilización. Desde su expulsión, tanto España como los propios árabes siempre fueron decayendo. ¿Quién puede imaginar cuál sería su prosperidad si ambos pueblos hubieran sido capaces de congeniar y si se hubiera hecho para instruirlos y moralizarlos todo cuanto se hizo para embrutecerlos? ¿De qué sirvieron tantos exilios, tantas hogueras y tantos cadalsos? Resulta muy cruel comprobar que la España cristiana fue inferior a la España pagana, luego a la España musulmana, inclusive a la España napoleónica. Por supuesto, no es culpa del cristianismo, sino de las pasiones humanas y de una fatalidad que, desde hace siglos, sólo le dio soberanos corruptos o faltos de inteligencia. ¡Mal haya de los países cuya prosperidad estriba menos en las instituciones que en el carácter de los individuos: los hombres cambian, pero las instituciones permanecen $!^{59}$

Por ende, a Boucher de Perthes, no le extraña que los españoles que viven en Argelia agradezcan su protección a Francia y quieran ser franceses. Su fervor civilizador hasta le lleva a declarar que la población española de Argel y de Orán es menos brutal y más laboriosa que la de España. ¿De dónde vendrá la diferencia? De las instituciones.

fasse moins pour les gouvernés que celui-ci», Ibid., pp. 193, 137.

${ }^{57}$ Ibid., pp. 193-194.

${ }^{58}$ Ibid., pp. 390, 451.

${ }^{59}$ "L'Afrique française sort de la barbarie, l'Espagne y retourne; nous rendons aux Maures ce qu'il nous avaient donné: la civilisation. Depuis leur expulsion, cette Espagne et les Maures eux-mêmes ont toujours été en décroissant. Qui peut dire où en serait aujourd'hui la civilisation arabe et la prospérité de la Péninsule si les deux peuples avaient pu s'entendre, et qu'on eût fait pour leur instruction et leur moralisation ce qu'on a fait pour les abrutir? A quoi ont servi tant d'exils, tant de bûchers, tant d'échafauds? Il est cruel de penser que l'Espagne chrétienne a élé inférieure à l'Espagne païenne, puis à l'Espagne musulmane, même à l'Espagne napoléonienne. Faut-il en accuser le christianisme? Non, mais les passions des hommes et la fatalité qui, depuis des siècles, ne lui a donné que des souverains corrompus ou inintelligents. Malheur au pays dont la prospérité repose moins sur les institutions que sur le caractère des individus: les hommes changent, les instituions restent», Ibid., pp. 441-442. 
Con una administración fuerte a la par que liberal, esta bella y valiente nación, hoy en día la más inútil y atrasada de Europa, pronto volvería a la civilización de la que se está alejando a diario. A falta de buenos gobernantes, necesitaría una buena constitución, o cuando menos una constitución, pero nunca ha podido conservar ninguna. Por ende, cuando existen tantas tierras baldías en España, los españoles que van a labrar las de África salen en busca de un buen gobierno. Francia tiene, pues, que aprovecharse de estos hombres que su país no sabe justipreciar ni utilizar: se convertirán en uno de los elementos de prosperidad de la colonia. Allí les llama un instinto de raza: en África reanudan con las costumbres y el clima de su patria, empero pierden su indolencia. Cabal prueba de ello es que en Bouffarik viven numerosos mahoneses y alicantinos que dejaron de ser perezosos, no bien salieron de su patria. A la larga, gracias a una justicia rápida e imparcial, también perderán su ferocidad. ${ }^{60}$

Boucher de Perthes, quien se interesa por la política hasta el punto de haber sido candidato para diputado en Francia y quien denigra a los gobiernos españoles, menciona reiteradamente que de nuevo se está produciendo una revolución en España. Empero, lo que no deja de sorprender al lector es que sólo cita los alborotos de paso, sin procurar enterarse más a fondo de lo que está ocurriendo. Es verdad que no domina el castellano. Habla el italiano con soltura, lo que, al cabo de unos días, le permite entender fragmentos de conversación y chapurrear unas pocas palabras, pero no tendrá la facultad de debatir asuntos complejos. Y, por lo demás, su estancia es demasiado corta para que pueda entender los problemas del país, aunque algunas observaciones no carecen de agudeza.

En resumidas cuentas, no conoce España. De ahí sus opiniones perentorias, en especial acerca de la pereza y de la crueldad de los españoles. Con todo, los hechos son tercos y sus generalizaciones abusivas son desmentidas por las cordiales relaciones que traba con los naturales, pese a sus dificultades para expresarse en castellano. $Y$ en esto reside el mayor atractivo del libro: el carácter bondadoso y generoso de Boucher de Perthes le incita a buscar siempre el aspecto positivo de los seres, sin condenarles nunca, por muy hoscos que le parezcan de entrada. Así, por ejemplo, terminada la cuarentena, por casualidad encuentra en una calle de Alicante al guarda en jefe, que le había hostigado y había intentado estafarlo todavía más que a sus compañeros de infortunio porque era extranjero. Ahora el vigilante se muestra muy afable, incluso convida a nuestro viajero a almorzar en su casa, oferta que éste rechaza con cortesía. Pero, sin rencor, acaba estimando que, a la postre, el funcionario no es tan mala persona, sólo es el producto de un sistema perverso que, por rutina, no sabe superar para imaginar otro mejor. ${ }^{61}$ 
En los transportes, cuando Boucher de Perthes ocupa un asiento bastante cómodo, lo propone sin vacilar a quien le aparece más cansado o más frágil, congraciándose así con los demás pasajeros que, agradecidos, se desvelan después por ayudarle en los trámites aduaneros o en conseguir cualquier información. En Madrid, paseando por el Prado, conoce a un joven oficial, a su mujer y a su hermana, felices de poder hablar francés con él y quienes le reciben muy afectuosamente en su casa. En Santa Pola, la población siente curiosidad por el francés y lo agasaja. O sea que sus relaciones personales con los españoles suavizan sus prejuicios.

Por otro lado, lo más conmovedor de su narración es su testimonio sobre un tremendo caso de cólera. Cerca de San Sebastián, huyendo de la epidemia, una joven madre de clase acomodada sube a la diligencia con su hija de unos cinco años, llamada Carolina, y un niño de poco más de un año, envuelto en una manta. Por falta de sitio, el niño va deslizándose poco a poco desde el regazo de su madre hacia las rodillas de Boucher de Perthes quien no lo rechaza, pese a que ya sufre agujetas por lo exiguo del coche, e inclusive, aguanta con indulgencia y resignación que el bebé le moje los pantalones.

[Le petit garçon], manquant de place sur sa mère, avait commencé à étendre ses jambes sur mes genoux. Les cuisses suivirent et successivement les reins; ce dont je fus averti par une humidité tiède qui, pénétrant l'étoffe de mes chausses, vint humecter ma peau. C'étail un fait accompli ct, toute réflexion faite, présumant que ce ne serail pas le dernier, jc me dis qu'il était sage d'en prendre mon parti (pp. 78-79).

De pronto, la criatura tiene náuseas y calambres y nuestro arqueólogo se da cuenta de que padece el cólera. Entonces, sin pensarlo dos veces, la abriga lo mejor que puede con su propio capote, para no alarmar a la madre y para que no se enteren los demás pasajeros, lo que significaría la expulsión inmediata de toda la familia.

\begin{abstract}
J'ai toujours l'enfant sur les genoux. Ses nausées augmentent et les secousses convulsives de ses jambes m'annoncent qu'il est tourmenté par des crampes. Je commence à soupçonner une triste vérité; j'examine ses yeux. Plus de doute, le malheureux a le choléra. Sa pauvre mère ne s'en doute pas. Je me garde bien de le lui dire. Je crains surtoul... l'effroi des autres voyageuses. La peur est sans pilié; elles auraient forcé le conducteur à laisser en route la pauvre mère et ses enfants. Certes, je ne les aurais pas abandonnés, je n'en eus pas un seul instant l'idée et, pourtant, la perspective d'avoir pendant trente heures encore ce pauvre petit sur mes genoux, de sentir ses spasmes et les mouvements convulsifs de ses membres endoloris, m'épouvantait plus que je ne saurais dire. Il fallait bien prendre son parti. Répétant donc comme le musulman «Dieu l'a voulu», j'enveloppai le moribond dans ma capote et le gardai sur moi (p. 95).
\end{abstract}

Conforme se va agravando el estado del niño, la madre se percata de lo irremediable y Boucher de Perthes sella con ella una especie de pacto de silencio, mientras él sigue cuidando discretamente de que el chiquillo pueda seguir respirando. Cuando sospecha 
que el niño ha muerto, está tan abatido que ni siquiera se atreve a cerciorarse de que el corazón ha dejado de latir y, al llegar a Madrid, entrega suavemente el pequeño cadáver a la madre sin aventurarse a mirarlo. Ella, aniquilada, no dice ni una palabra, pero le besa la mano con agradecimiento. Por muy afligido que está, Boucher de Perthes no quiere abandonarla, sino que se propone acompañarla en coche hasta su casa, pero la espera un conocido suyo que se hace cargo de ella y de sus hijos:

La pauvre mère était tombće dans une sorte d'anéantissement moral. Elle caressait par moment sa petite, mais n'osait pas regarder son fils. Je ne l'osais pas non plus. Cependant, je l'avais toujours sur mes genoux, enveloppé de manière à lui laisser la respiration. Cette respiration, je ne l'entendais plus. Quelques convulsions plus fortes s'étaient manifestées; depuis près de deux heures, je n'en sentais plus. J'aurais pu, en plaçant ma main sur son cœur, m'assurer s'il battait encore, mais, quelque que faible que fût mon espoir, je ne voulais pas le perdre. La même raison, sans doute, arrêtait la mère. Ni elle ni moi ne voulions savoir la vérité. Ce fut ainsi que nous demeurâmes une heure et demie, sans parler, sans faire un geste.

Nous gardions encore ce silence et cette immobilité quand, entrés dans Madrid, la voiture s'arrêta au bureau de la diligence. Nous fûmes invités à descendre. Je pris l'enfant sans le regarder. Je le posai doucement sur les genoux de la mère. La pauvre fermme ne dit pas une parole, ne poussa pas un soupir, mais me prit la main et la porta à ses lèvres. Je serrai la sienne, et je descendis le couur gros et les larmes aux yeux.

Mon intention n'était pourtant pas de l'abandonner el, bien qu'il m'en coûtât beaucoup d'assister à la scène qui allait suivre, je demandai une voiture pour la conduire au logis qu'elle indiquerait... Un homme parut; il était probablement de la connaissance de la dame, car elle prononça son nom et lui remit Carolina (pp. 103-104).

Esta terrible anécdota pone de realce todo el interés del relato de Boucher de Perthes: su profunda humanidad que siempre le conduce a prestar atención y auxilio a los humildes y a los desgraciados. En este sentido, la mirada crítica con que juzga a España y, ante todo a sus gobernantes, se convierte en muy benévola hacia los seres. A los zafios, y hasta a aquellos que le parecen poco recomendables, los disculpa por considerar que sus defectos proceden de las disfunciones generadas por una administración nefasta. Nuestro filántropo está convencido de que si el gobierno se preocupara de veras por dar un impulso al país, por remediar la pobreza de la mayoría de los ciudadanos, al hacer a los españoles más felices, también los haría menos descuidados y más finos, 
